\title{
A Periodically Forced Beverton-Holt Equation
}

\author{
J.M. CUSHING ${ }^{a, \star}$ and SHANDELLE M. HENSON ${ }^{b}$ \\ a Department of Mathematics, University of Arizona, Tucson, AZ 85721, USA; \\ ${ }^{\mathrm{b}}$ Department of Mathematics, Andrews University, Berrien Springs, MI \\ 49104, USA
}

(Received 23 January 2002; In final form 8 February 2002)

For $r>1$ and $K>0$ the difference equation

$$
x_{t+1}=\frac{r K}{K+(r-1) x_{t}} x_{t}, \quad t=0,1,2, \ldots
$$

has a unique positive equilibrium $K$ and all solutions with $x_{0}>0$ approach $K$ as $t \rightarrow \infty$. This equation (known as the Beverton-Holt equation) arises in applications to population dynamics, and in that context $K$ is the "carrying capacity" and $r$ is the "inherent growth rate". A modification of this equation that arises in the study of populations living in a periodically (seasonally) fluctuating environment replaces the constant carrying capacity $K$ by a periodic sequence $K_{t}$ of positive carrying capacities.

*Corresponding author. E-mail: cushing@math.arizona.edu 
Thus, we have a periodically forced Beverton-Holt equation

$$
x_{t+1}=\frac{r K_{t}}{K_{t}+(r-1) x_{t}} x_{t}
$$

in which the sequence $K_{0}, K_{1}, \ldots$ of positive numbers is periodic with a base period $p$, i.e. $K_{t+p}=K_{t}>0$ for all $t \geq 0$ and a (minimal) integer $p \geq 1$. Keep the inherent growth rate $r>1$ constant and consider the following assertions.

(a) Equation (1) has a positive $p$-periodic solution $y_{t}>0$, and it is globally attracting for $x_{0}>0$.

(b) If $p>2$, the strict inequality $a v\left(y_{t}\right)<a v\left(K_{t}\right)$ holds. Here $a v$ denotes the average of a periodic cycle, e.g.

$$
a v\left(y_{t}\right)=\frac{1}{p} \sum_{t=0}^{p-1} y_{t} .
$$

These assertions are of ecological interest because they imply a fluctuating habitat is deleterious to a population in the sense that the average population size, in the long run, is less in a periodically oscillating habitat than it is in a constant habitat with the same average.

As pointed out above, (a) holds when $p=1$ (i.e. $K_{t}=K$ is a constant). However, when $p=1$ assertion (b) is false, since in that case $y_{t}=K$ and hence $a v\left(y_{t}\right)=a v\left(K_{t}\right)$. On the other hand, it is known that both (a) and (b) are true for $p=2[1]$. We conjecture (a) and (b) are in fact true for all periods $p \geq 2$. However, it remains an open problem to prove (or disprove) these assertions for $p \geq 3$.

\section{References}

[1] Cushing, J.M. and Shandelle M., Henson, Global dynamics of some periodically forced, monotone difference equations, Journal of Difference Equations and Applications 7 (2001), 859-872. 
Copyright of Journal of Difference Equations \& Applications is the property of Taylor \& Francis Ltd and its content may not be copied or emailed to multiple sites or posted to a listserv without the copyright holder's express written permission. However, users may print, download, or email articles for individual use. 